\title{
KELAYAKAN MOBILE LEARNING MEDIA PADA MATERI FISIKA INTI DAN RADIOAKTIVITAS
}

\author{
Dandan Luhur Saraswati \\ Pendidikan Fisika, Fakultas Matematika dan IPA, Universitas Indraprasta PGRI \\ Jl. Raya Tengah No. 80 Gedong, Pasar Rebo, Jakarta Timur, 13760, Indonesia \\ E-mail: dandanluhur@gmail.com
}

\begin{abstract}
ABSTRAK
Pada pokok bahasan fisika inti dan radioaktivitas sangat diperlukan penjelasan secara audio visual yang dapat mempermudah peserta didik dalam memahami materi. Oleh karena itu, diperlukan media pembelajaran yang dapat menampilkan audio visual agar dapat membantu peserta didik dalam pembelajaran secara mandiri. Salah satu media pembelajaran yang dapat digunakan adalah aplikasi android. Tujuan dalam penelitian ini adalah mengetahui kelayakan dari media pembelajaran fisika berbasis mobile learning pada materi fisika inti dan radioaktivitas yang dikembangkan. Tahapan pengembangan produk dilakukan berdasarkan enam tahap, yaitu concept, design, material collecting, assembly, testing, dan distribution. Teknik pengumpulan data yang digunakan adalah kuesioner evaluasi produk. Kuesioner evaluasi produk digunakan untuk menilai produk pengembangan oleh ahli materi dan ahli media. Hasil uji validasi oleh ahli materi didapatkan skor $83,27 \%$ dan ahli media didapatkan skor 88,15\%. Berdasarkan hasil uji kelayakan maka media pembelajaran fisika berbasis aplikasi android pada pokok bahasan fisika inti dan radioaktivitas memiliki nilai rata-rata $85,71 \%$ dengan interpretasi sangat baik. Sehingga, produk ini dapat diujicoba lapangan bagi pengguna agar didapatkan produk yang layak digunakan sebagai alternatif media pembelajaran di kelas.
\end{abstract}

Kata kunci: media pembelajaran, mobile learning, android

\begin{abstract}
Required explanation of core physics and radioactivity through audio-visual learning media that helps students learn independently. The purpose of this study is to determine the feasibility of mobile learning media on the subject of core physics and radioactivity material. The stages of product development are: concept, design, material collection, assembly, testing, and distribution. Data collection techniques used were product evaluation questionnaires by material and media experts. The score of the results of the validation test for material experts was $83.27 \%$ and the media experts were $88.15 \%$. Based on the results of the feasibility test, physics learning media based on Android applications on the subject of core physics and radioactivity have an average value of $85.71 \%$ with the interpretation of "very good". This product can be tested in the field to get products that are suitable for use as alternative learning media in the classroom.
\end{abstract}

Keywords: learning media, mobile learning, android

DOI: http://dx.doi.org/10.15575/jtlp.v4i2.5606

Received: 6 Agustus 2019 ; Accepted: 19 Agustus 2019 ; Published: 30 Agustus 2019 


\section{PENDAHULUAN}

Perkembangan teknologi memberikan andil yang sangat besar dalam perkembangan ilmu pengetahuan khususnya dalam perkembangan media pembelajaran saat ini dan masa yang akan datang (Mardiyasa dkk, 2016; Saraswati, 2018). Dalam pandangan tradisional, konsep pembelajaran di sekolah selalu diilustrasikan melalui tatap muka pertemuan antara guru dan siswa di kelas (Saraswati dkk, 2018). Dalam perkembangannya Widada \& Rosyidi (2018) menyatakan bahwa media pembelajaran menempati posisi yang cukup penting dalam sistem pembelajaran. Penggunaan media pembelajaran dapat membantu keterbatasan pendidik dalam menyampaikan informasi maupun keterbatsan jam pembelajaran di kelas (Yektyastuti \& Ikhsan, 2016). Keuntungan lain dengan adanya penggunaan media pembeajaran adalah dapat meningkatkan pengetahuan dan keterampilan peserta didik (Priscylio, 2019). Salah satu media pembelajaran yang sedang tren adalah mobile learning yang dapat berupa aplikasi android. Android merupakan salah satu sistem operasi mobile (Saraswati, Mulyaningsih, \& Widiyatun 2018) (Matsun, Ramadhani, \& Lestari, 2018). Melalui aplikasi android pula peserta didik dapat belajar dimanapun dan kapanpun (Purbasari, Kahfi, \& Yunus 2013).

Saat ini aplikasi media pembelajaran berbasis android telah tersedia di Playstore. Namun, aplikasi-aplikasi yang telah tersedia, biasanya hanya berkutat pada tulisan, gambar ataupun animasi. Sedangkan suara yang digunakan biasanya hanya berupa backsound musik. Padahal, setiap manusia memiliki cara menyerap informasi (modalitas) yang mendominasi yang berbeda-beda. Terdapat tiga cara seseorang untuk menyerap informasi, yaitu visual, auditori dan kinestetik. Visual berkaitan dengan penglihatan, auditori berkaitan dengan pendengaran, sedangkan kinestetik berkaitan dengan gerakan. Oleh karena itu, penjelasan melalui suara cukup penting, sehingga mengakomodasi untuk peserta didik-peserta didik yang memiliki modalitas auditorial. Agar proses pembelajaran menggunakan informasi multimedia menjadi efisien, perlu untuk memilih informasi media yang relevan dan mengaturnya menjadi model verbal dan gambar (Khairani, Sutusna, \& Suyanto 2019).

Dengan menggunakan aplikasi media pembelajaran berbasis Android, diharapkan peserta didik akan lebih mudah mengamati, menalarkan, serta menyimpulkan konsepkonsep Fisika yang ada, khususnya pada pokok bahasan fisika inti dan radioaktivitas, karena pola belajar akan menjadi lebih menarik, interaktif dan mengakomodir modalitas peserta didik. Hal ini didukung oleh hasil penelitian yang dilakukan oleh Taufik \& Kristanto (2018) tentang keefektifan penggunaan mobile learning berbasis android pada mata pelajaran fisika materi listrik arus searah. Hasil positif juga dikemukakan oleh Damayanti, dkk (2018) yaitu Pengembangan media pembelajaran fisika berupa buku saku berbasis android layak digunakan dalam pembelajaran. Kelayakan produk berdasarkan penilaian ahli materi dan ahli media dengan penilaian persentase rata-rata $79,85 \%$ dalam kategori layak dan 87,96 \% dalam kategori sangat layak.

Mempelajari fisika membutuhkan berbagai cara efektif untuk mengembangkan kemampuan berpikir siswa (Saraswati, dkk, 2018). Hasil penelitian yang dilakukan Ridwan (2019) oleh menyatakan bahwa proses pembelajaran yang masih dilakukan secara konvensional berdampak pada nilai rata-rata ulangan harian IPA kurang dari 30\% yang dapat mencapai KKM. Mengembangkan kemampuan berpikir dalam pembelajaran fisika juga dapat dilakukan dengan kegiatan praktikum baik secara nyata maupun virtual. Seperti penelitian yang dilakukan Araswati (2016) mengenai penggunaan Logger Pro untuk analisis gerak harmonik sederhana pada sistem pegas massa, kegiatan yang dilakukan berupa praktikum virtual dengan memanfaatkan video based laboratory. 
Pada pokok bahasan fisika inti dan radioaktivitas sangat diperlukan penjelasan secara audio visual yang dapat mempermudah peserta didik dalam memahami materi. Oleh karena itu, diperlukan media pembelajaran yang dapat menampilkan audio visual agar dapat membantu peserta didik dalam pembelajaran secara mandiri. Salah satu media pembelajaran yang dapat digunakan adalah aplikasi android. Tujuan dalam penelitian ini adalah mengetahui kelayakan dari media pembelajaran fisika berbasis mobile learning pada materi fisika inti dan radioaktivitas yang dikembangkan.

\section{METODE PENELITIAN}

Metode penelitian yang digunakan dalam penelitian ini adalah metode penelitian pengembangan (R\&D). Tahapan pengembangan produk dilakukan berdasarkan enam tahap, yaitu concept, design, material collecting, assembly, testing, dan distribution (Sutopo, 2003). Teknik pengumpulan data yang digunakan adalah kuesioner evaluasi produk. Kuesioner evaluasi produk digunakan untuk menilai produk pengembangan oleh ahli materi dan pembelajaran dan ahli media. Adapun kisikisi angket yang akan diberikan kepada para ahli media terdiri dari 15 butir pernyataan yang terbagi dalam 3 dimensi. Kisi-kisi angket yang akan diberikan kepada para ahli materi terdiri dari 22 butir pernyataan yang terbagi dalam 3 dimensi seperti pada tabel 1 dan pada tabel 2 .

Tabel 1. Kisi-kisi uji kelayakan ahli media

\begin{tabular}{clcc}
\hline Dimensi & Indikator & $\begin{array}{c}\text { Jumlah } \\
\text { Soal }\end{array}$ & $\begin{array}{c}\text { Nomor } \\
\text { Soal }\end{array}$ \\
\hline $\begin{array}{c}\text { Kualitas isi } \\
\text { (konten) dan } \\
\text { tujuan }\end{array}$ & Ketepatan & 1 & 1 \\
\cline { 2 - 4 } & $\begin{array}{l}\text { Kesesuaian } \\
\text { dengan situasi } \\
\text { peserta didik }\end{array}$ & 1 & 2 \\
\hline $\begin{array}{c}\text { Kualitas } \\
\text { Instruksional }\end{array}$ & $\begin{array}{l}\text { Memberikan } \\
\text { kesempatan } \\
\text { untuk belajar }\end{array}$ & 1 & 3 \\
\hline
\end{tabular}

\begin{tabular}{|c|c|c|c|}
\hline Dimensi & Indikator & $\begin{array}{l}\text { Jumlah } \\
\text { Soal }\end{array}$ & $\begin{array}{c}\text { Nomor } \\
\text { Soal }\end{array}$ \\
\hline & $\begin{array}{l}\text { Kualitas } \\
\text { interaksi guru } \\
\text { dan peserta } \\
\text { didik }\end{array}$ & 1 & 4 \\
\hline & $\begin{array}{l}\text { Membawa } \\
\text { dampak bagi } \\
\text { guru dan } \\
\text { pembelajaran- } \\
\text { nya }\end{array}$ & 1 & 5 \\
\hline & $\begin{array}{l}\text { Memotivasi } \\
\text { peserta didik }\end{array}$ & 1 & 6 \\
\hline & $\begin{array}{l}\text { Efektif dalam } \\
\text { penggunaan } \\
\text { media } \\
\text { pembelajaran }\end{array}$ & 1 & 7 \\
\hline \multirow{5}{*}{$\begin{array}{l}\text { Kualitas } \\
\text { Teknis }\end{array}$} & Keterbacaan & 2 & 8,9 \\
\hline & $\begin{array}{l}\text { Kemudahan } \\
\text { untuk } \\
\text { difahami }\end{array}$ & 2 & 10,11 \\
\hline & $\begin{array}{l}\text { Kualitas } \\
\text { tampilan/ } \\
\text { tayangan }\end{array}$ & 2 & 12,13 \\
\hline & $\begin{array}{l}\text { Kejelasan } \\
\text { suara }\end{array}$ & 1 & 14 \\
\hline & $\begin{array}{l}\text { Mudah } \\
\text { digunakan }\end{array}$ & 1 & 15 \\
\hline
\end{tabular}

Tabel 2. Kisi-kisi uji kelayakan ahli materi

\begin{tabular}{|c|c|c|c|}
\hline Dimensi & Indikator & $\begin{array}{c}\text { Jumlah } \\
\text { Soal }\end{array}$ & $\begin{array}{c}\text { Nomor } \\
\text { Soal }\end{array}$ \\
\hline \multirow{7}{*}{$\begin{array}{c}\text { Kualitas isi } \\
\text { (konten) dan } \\
\text { tujuan }\end{array}$} & Ketepatan & 3 & $1,2,3$ \\
\hline & Aktualitas & 1 & 4 \\
\hline & Kontekstualitas & 1 & 5 \\
\hline & $\begin{array}{l}\text { Kedalaman } \\
\text { Materi }\end{array}$ & 1 & 6 \\
\hline & Sistematis & 1 & 7 \\
\hline & $\begin{array}{l}\text { Konsistensi } \\
\text { evaluasi dengan } \\
\text { tujuan } \\
\text { pembelajaran }\end{array}$ & 1 & 8 \\
\hline & $\begin{array}{l}\text { Kesesuaian } \\
\text { dengan kondisi } \\
\text { peserta didik }\end{array}$ & 1 & 9 \\
\hline \multirow{3}{*}{$\begin{array}{c}\text { Kualitas } \\
\text { instruksional }\end{array}$} & $\begin{array}{l}\text { Memberikan } \\
\text { kesempatan } \\
\text { belajar }\end{array}$ & 1 & 10 \\
\hline & $\begin{array}{l}\text { Memotivasi } \\
\text { peserta didik }\end{array}$ & 1 & 11 \\
\hline & Kualitas & 1 & 12 \\
\hline
\end{tabular}




\begin{tabular}{clcc}
\hline \multirow{2}{*}{ Dimensi } & \multicolumn{1}{c}{ Indikator } & $\begin{array}{c}\text { Jumlah } \\
\text { Soal }\end{array}$ & $\begin{array}{c}\text { Nomor } \\
\text { Soal }\end{array}$ \\
\hline & $\begin{array}{l}\text { interaksi peserta } \\
\text { didik dan guru }\end{array}$ & & \\
\cline { 2 - 3 } & $\begin{array}{l}\text { Efektif dalam } \\
\text { penggunaan } \\
\text { media } \\
\text { pembelajaran }\end{array}$ & 1 & 13 \\
& $\begin{array}{l}\text { Membawa } \\
\text { dampak bagi }\end{array}$ & 1 & 14 \\
& $\begin{array}{l}\text { guru dan } \\
\text { pembelajarannya }\end{array}$ & & \\
\hline & Keterbacaan & 2 & 15,16 \\
\cline { 2 - 4 } Kualitas & $\begin{array}{l}\text { Kemudahan } \\
\text { bahasa untuk } \\
\text { deknik }\end{array}$ & 2 & 17,18 \\
\cline { 2 - 4 } & $\begin{array}{l}\text { Kualitas } \\
\text { tayangan }\end{array}$ & 2 & 19,20 \\
\cline { 2 - 4 } & Kejelasan suara & 1 & 21 \\
\cline { 2 - 4 } & $\begin{array}{l}\text { Mudah } \\
\text { digunakan }\end{array}$ & 1 & 22 \\
\hline
\end{tabular}

Teknik analisis data menggunakan interprestasi data dari kuesioner ahli materi dan ahli media. Batas baik dan tidaknya kualitas media pembelajaran fisika pada pokok bahasan fisika inti dan radioaktivitas dengan menggunakan mobile learning dengan menggunakan interpretasi skor yang dihitung dengan rumus 1 dan keterangan interpretasi dapat dilihat pada tabel 3 .

$\%$ Interpretasi skor $=\frac{\sum \text { Skor perolehan }}{\sum \text { Skor maksimal }} \times 100 \%$

Tabel 3. Interpretasi skor

\begin{tabular}{cc}
\hline Presentasi Skor & Keterangan \\
\hline $0 \%-25 \%$ & Sangat Kurang \\
\hline $26 \%-50 \%$ & Kurang \\
\hline $51 \%-75 \%$ & Baik \\
\hline $76 \%-100 \%$ & Sangat Baik \\
\hline
\end{tabular}

\section{HASIL DAN PEMBAHASAN}

\section{Pengumpulan Informasi}

Pengumpulan informasi ini terkait dengan kebutuhan di lapangan, dalam hal ini adalah pembelajaran di sekolah. Sehingga perlu dirumuskan indikator-indikator yang merupakan penjabaran dari kompetensi inti dan kompetensi dasar yang tertampil pada tabel 4 .
Tabel 4. Kompetensi Inti dan Kompetensi Dasar

Kompetensi Inti

\section{Kompetensi Dasar}

3. Memahami, menerapkan, dan menjelaskan pengetahuan faktual, konseptual, prosedural, dan metakognitif dalam ilmu pengetahuan, teknologi, seni, budaya, dan humaniora dengan wawasan kemanusiaan, kebangsaan, kenegaraan, dan peradaban terkait penyebab fenomena dan kejadian, serta menerapkan pengetahuan prosedural pada bidang kajian yang spesifik sesuai dengan bakat dan minatnya untuk memecahkan masalah.

4. Mengolah, menalar, menyaji, dan mencipta dalam ranah konkret dan ranah abstrak terkait dengan pengembangan dari yang dipelajarinya di sekolah secara mandiri serta bertindak secara efektif dan kreatif, dan mampu menggunakan metoda sesuai kaidah keilmuan.

3.11Mendeskripsikan karakteristik inti atom, radioaktivitas, dan pemanfaatannya dalam teknologi

Sumber : Widodoaji (2013)

Dari kompetensi inti dan kompetensi dasar pada tabel 4, dapat dijabarkan indikator-indikator dalam pembelajaran, yaitu:

1. Peserta didik dapat menjelaskan partikelpartikel penyusun inti atom.

2. Peserta didik dapat menjelaskan konsep satuan massa atom.

3. Peserta didik dapat mengkonversi satuan massa dari kilogram ke satuan massa atom dan sebaliknya.

4. Peserta didik dapat menjelaskan konsep notasi atom. 
5. Peserta didik dapat menjelaskan konsep isotop.

6. Peserta didik dapat menghitung besar jarijari inti atom.

7. Peserta didik dapat menjelaskan konsep defek massa dan energi ikat inti atom.

8. Peserta didik dapat menghitung defek massa dan energi ikat inti.

9. Peserta didik dapat menjelaskan grafik energi ikat per nukleon.

10. Peserta didik dapat menjelaskan konsep radioaktivitas.

11. Peserta didik dapat menjelaskan jenis-jenis peluruhan dan karakteristiknya.

12. Peserta didik dapat melengkapi suatu reaksi peluruhan.

13. Peserta didik dapat menghitung aktivitas yang tersisa dari sebuah inti atom yang tidak stabil.

14. Peserta didik dapat menjelaskan konsep waktu paruh.

15. Peserta didik dapat menghitung besar waktu paruh.

16. Peserta didik dapat menghitung jumlah inti atom yang tersisa dari sebuah peluruhan.

17. Peserta didik dapat menjelaskan konsep reaksi inti atom.

18. Peserta didik dapat menjelaskan konsep reaksi fisi inti atom dan contohnya.

19. Peserta didik dapat menjelaskan pemanfaatkan reaksi fisi dalam PLTN.

20. Peserta didik dapat menjelaskan konsep reaksi fusi inti atom dan contohnya.

21. Peserta didik dapat menjelaskan reaksi fusi yang terdapat dalam matahari.

Dari indikator-indikator yang telah dijabarkan dari kompetensi inti dan kompetensi dasar pada tabel 4, kemudian dibuatlah sebuah mindmapping. Mindmapping ini digunakan untuk mempermudah alur materi sehingga terdapat sebuah keterkaitan antara satu topik pembahasan dengan topik pembahasan yang lain. Mindmapping terkait dengan pokok bahasan fisika inti dan radioaktivitas terlihat pada gambar 1.

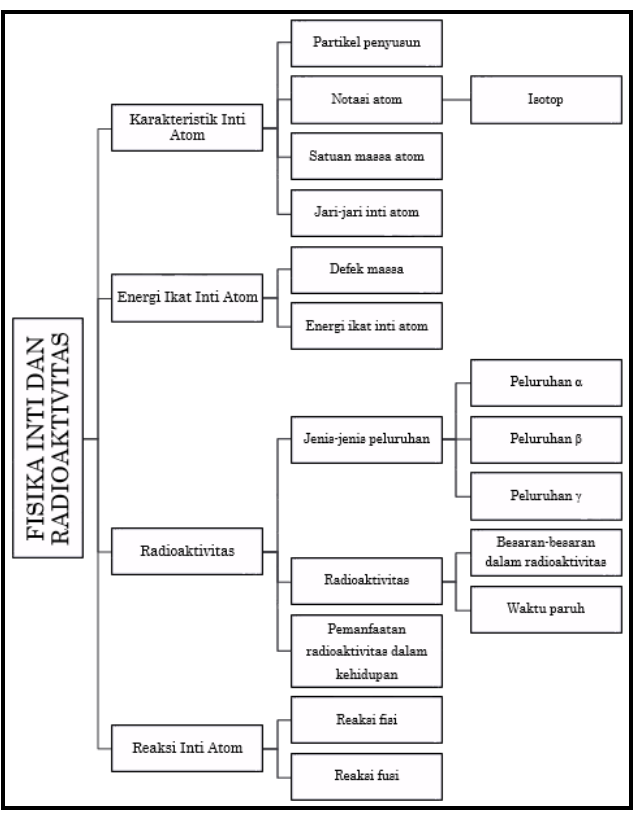

Gambar 1. Mindmapping materi

\section{Desain Produk}

Setelah melakukan pengumpulan informasi dan melakukan inventarisir materi, kemudian dilakukan pembuatan media. Pengembangan mobile learning hanya dilakukan sampai pada tahap kelima yaitu testing. Adapun kelima tahapan yang dilakukan, yaitu concept (konsep), design (desain), material collecting (pengumpulan bahan), assembly (penggabungan), testing (percobaan).

\section{a. Concept}

Tahap konsep yaitu menentukan tujuan, termasuk identifikasi audiens, macam aplikasi (presentasi, interaktif, dan lain-lain), tujuan aplikasi (informasi, hiburan, pelatihan, dan lainlain) dan spesifikasi umum. Dalam tahapan ini juga dilakukan inventarisir materi fisika inti untuk peserta didik SMA kelas XII IPA. Salah satu inventarisir materi dapat dilihat pada gambar 2 . 


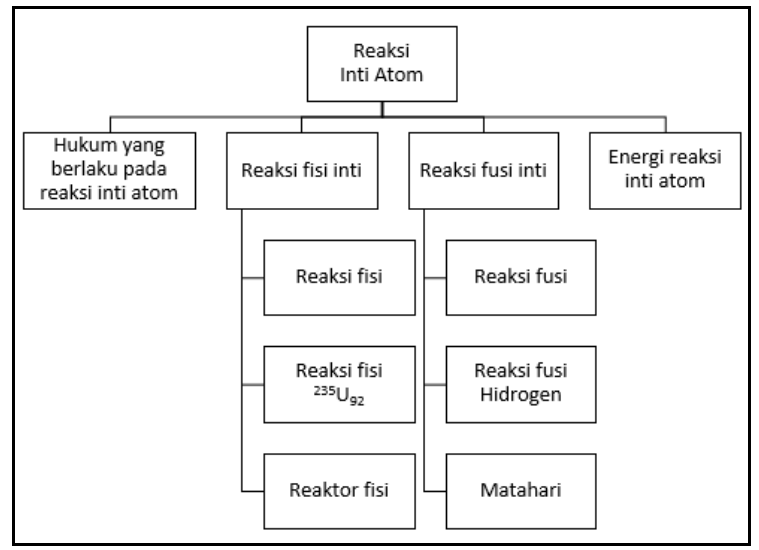

Gambar 2. Bagan inventarisir pada materi reaksi inti atom

\section{b. Design}

Langkah kedua yaitu design atau desain, terdapat 3 macam perancangan, yaitu desain berbasis multimedia, desain struktur navigasi, dan desain berorientasi objek. Media ini menggunakan desain struktur navigasi. Struktur navigasi memberikan gambaran link dari halaman satu ke halaman lainnya. Jenis struktur navigasi yang digunakan adalah desain linier. Model yang digunakan adalah top-down design.

Konsep navigasi ini dimulai dari satu node yang menjadi halaman utama atau halaman awal. Dari halaman tersebut dapat dibuat beberapa cabang ke halaman-halaman level 1. Bila diperlukan, dari tiap halaman level 1 dapat dikembangkan menjadi beberapa cabang lagi. Hal ini seperti struktur organisasi dalam perusahaan. Navigasi linier biasanya digunakan pada beberapa macam aplikasi seperti presentasi, aplikasi computer based-training dan aplikasi yang memerlukan informasi berurutan.

Materi yang disampaikan dalam mobile learning media ini mencakup fisika inti dan radioaktivitas. Pada materi fisika inti dimulai dari pengenalan struktur atom dan inti atom. Kemudian dilanjutkan tentang konsep satuan massa atom dan inti atom. Kemudian dilanjutkan tentang konsep satuan massa atom (sma atau $\mu$ ) sebagai besaran yang digunakan untuk menyatakan besar massa atom, inti atom dan partikelpartikel penyusunnya. Selanjutnya, materi dilanjutkan dengan materi energi ikat inti. Materi energi ikat inti mencakup defek massa yang terjadi pada inti atom, dan energi ikat inti atom. Materi selanjutnya adalah radioaktivitas. Materi radioaktivitas meliputi radioaktivitas, persamaan peluruhan, waktu paruh, dan peluruhan inti atom yang terbagi atas peluruhan alfa, peluruhan beta, dan peluruhan gama. Materi terakhir pada aplikasi ini adalah reaksi inti atom. Reaksi inti atom meliputi hukum yang berlaku pada reaksi inti atom, reaksi fisi, reaksi fusi dan energi reaksi inti atom.

\section{c. Material collecting}

Pada tahapan material collecting, dilakukan pengumpulan bahan seperti gambar, animasi, audio, foto, dan video yang diperlukan untuk tahap berikutnya. Pemilihan bahan disesuaikan dengan kebutuhan. Kebutuhan bahan meliputi grafik, teks dan animasi.

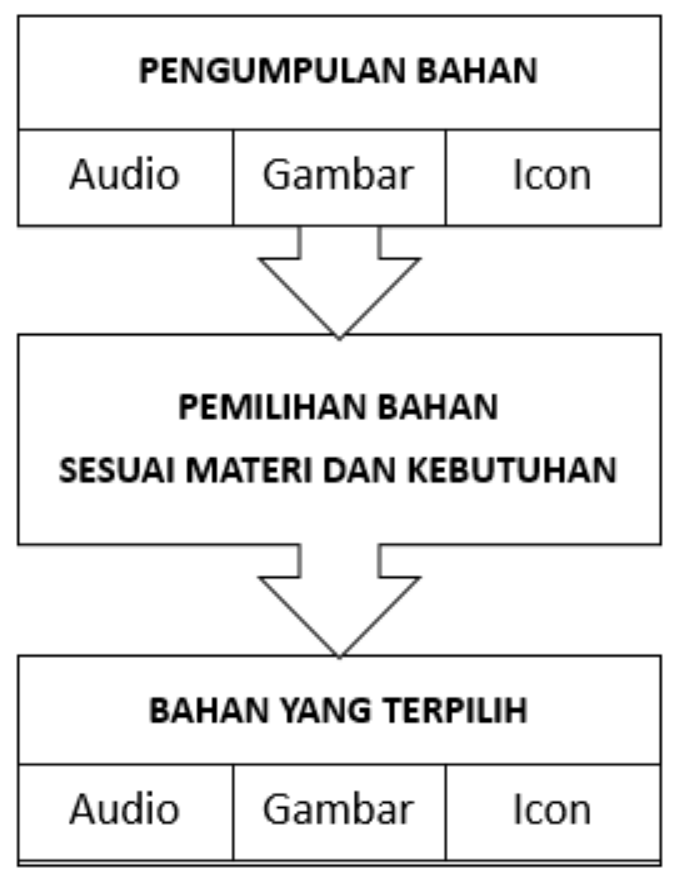

Gambar 3. Diagram alir pemilihan bahan

Animasi yang diperlukan dibuat dengan menggunakan Adobe Animate yang merupakan program dasar pembuatan aplikasi. Audio atau suara yang digunakan didapatkan dengan merekam suara. Perekaman audio menggunakan microphone yang dihubungkan ke laptop dan diedit dengan menggunakan program Cool Edit 
Pro 2.0. Perekaman suara menggunakan amplitudo sekitar $6 \mathrm{~dB}$, untuk menghindari suara pecah dan sumbang karena terlalu besar dan suara terlalu kecil untuk didengar sehingga tidak terlalu jelas.

\section{d. Assembly}

Tahap assembly atau pembuatan merupakan tahap penggabungan semua bahan yang telah disiapkan sehingga menjadi suatu kesatuan dalam bentuk aplikasi Android. Pembuatan media ini menggunakan basis program Adobe Animate dan ditunjang dengan beberapa program lainnya, seperti Adobe Photoshop untuk mengedit gambar dan grafik, Cool Edit Pro 2.0 untuk menginput atau merekam suara dan mengedit suara dari hasil rekaman

\section{e. Testing}

Pada tahap testing, media yang sudah selesai digabungkan dites, apakah ada bagian-bagian yang salah ataupun script yang tidak berjalan semestinya. Adobe Animate memiliki fitur yang akan menjelaskan ketika ada script yang tidak benar ataupun tidak bekerja dengan semestinya.
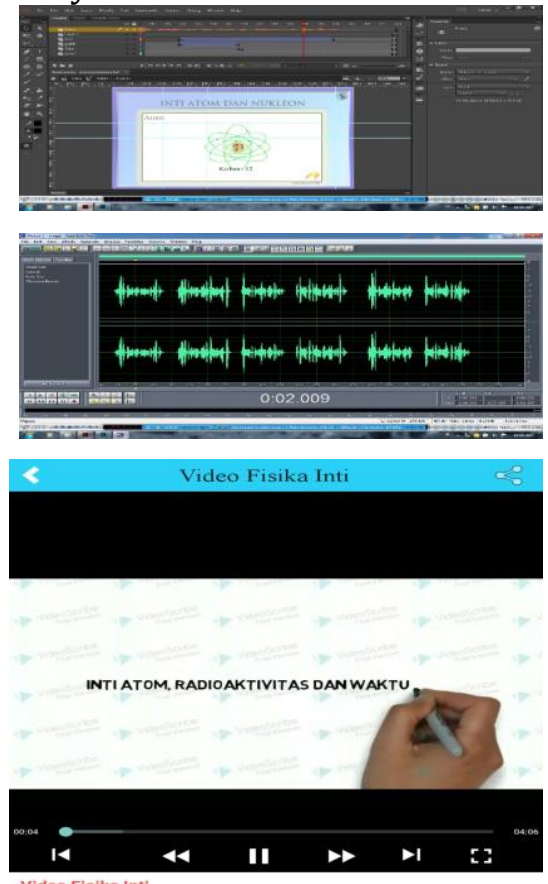

Gambar 4. Pembuatan gambar, proses perekaman, tampilan hasil produk
Pada gambar 4 dapat dilihat rangkaian proses pembuatan produk yang terdiri atas pembuatan gambar, proses perekaman, tampilan hasil produk.

\section{Kelayakan Produk}

Tahapan selanjutnya adalah memvalidasi atau menguji kelayakan produk yang telah dibuat. Validasi produk ini dilakukan dengan memberikan angket kepada ahli yang terbagi menjadi dua, yaitu ahli materi dan ahli media. Ahli materi adalah 4 orang dosen program studi pendidikan fisika Universitas Indraprasta PGRI rata-rata nilai yang didapatkan adalah $83,27 \%$ yang berarti media ini menurut para ahli sangat layak konten (isi) yang terdiri dari tujuh indikator, kualitas instruksional terdiri atas lima indicator dan kualitas teknik terdiri dari lima indikator. Berdasarkan hasil uji ini menyatakan bahwa dari segi materi produk ini layak untuk dilakukan uji penggunaan agar didapatkan hasil yang layak untuk diimplementasikan di kelas sebagai media pembelajaran.

Uji kelayakan selanjutnya adalah uji ahli media. Ahli media adalah dosen yang memiliki kompetensi desain, teknologi pendidikan, dan media pembelajaran. Ahli media terdiri dari 4 dosen, yaitu 3 dosen program studi desain komunikasi visual (DKV), 1 dosen pendidikan fisika di Universitas Indraprasta PGRI. Skor ratarata hasil validasi oleh ahli media adalah $88,15 \%$ dengan interpretasi sangat baik. Dengan demikian, berarti media ini menurut para ahli media layak untuk diuji kepada pengguna.

Dengan demikian, setelah melakukan uji validasi ahli materi dan ahli media didapatkan nilai kelayakan produk yang dikembangkan dengan nilai rata-rata $85,71 \%$ dengan interpretasi sangat baik. Sehingga produk ini dapat diujicoba lapangan bagi pengguna agar didapatkan produk yang layak digunakan sebagai alternatif media pembelajaran di kelas sebagai pengimplementasian media pembelajaran yang dikembangkan. 
Hasil positif mengenai mobile learning media yaitu penelitian yang dilakukan oleh Megawati (2014) menyatakan bahwa $e$-book pembelajaran dapat digunakan untuk melatih kompetensi membaca, menulis, berbicara dan menyimak. Melalui $e$-book ini diharapkan dapat memberikan informasi yang tidak dapat dilakukan dengan cara konvensional.

Hasil penelitian positip lainnya mengenai pengembangan media pembelajaran Mobile learning media Fisika berbasis multimedia yang digunakan dalam pembelajaran fisika pada materi alat-alat optik untuk meningkatkan hasil belajar peserta didik (Hayati, Budi, \& Handoko, 2015) didapatkan kesimpulan sebagai berikut: (1) Hasil uji kelayakan kepada ahli dan pengguna didapatkan rata-rata persentase secara keseluruhan adalah 95,87\% dengan interpretasi sangat baik. Hal ini menunjukan bahwa media Mobile learning media Fisika berbasis multimedia yang dibuat layak digunakan dalam pembelajaran fisika; (2) Hasil uji perbedaan didapatkan bahwa nilai t hitung adalah 10,00 dan nilai $t$ tabel adalah 2,03. Jika $\mathrm{t}$ hitung $>\mathrm{t}$ tabel maka H0 ditolak, sehingga dapat disimpulkan terdapat perbedaan nilai rata-rata antara tes awal dan tes akhir setelah menggunakan media Mobile learning media Fisika; (3) Media Mobile learning media Fisika berbasis multimedia dapat meningkatkan hasil belajar peserta didik, dimana nilai rata-rata tes awal 36,11 pada kelas eksperimen sebagai kelas pengguna media meningkat menjadi 84,44 dengan kenaikan 57,23 \%.

Pengembangan media pembelajaran interaktif mata kuliah medan elektromagnetik yang dilakukan oleh Ali (2009) menghasilkan media pembelajaran yang dikembangkan memenuhi kriteria sangat baik berdasarkan penilaian ahli media pembelajaran yang diukur berdasarkan kualitas yang meliputi aspek operasional, tampilan dan interaksi dengan rata-rata 3,74 skala linkert sehingga layak digunakan untuk belajar mandiri. Penelitian ini juga menghasilkan respon mahasiswa terhadap media pembelajaran yang dikembangkan sangat baik untuk mendukung belajar mandiri yang ditunjukkan dengan skor rata-rata penilaian 3,23 pada skala linkert,

Mobile learning media ini dapat diimplementasikan sebagai sumber belajar mandiri yang dapat membantu peserta didik dalam meningkatkan kompetensi atau pemahaman secara kognitif yang dimilikinya (Gunadharma, 2011). Mobile learning media ini juga dapat digunakan dimana saja dan kapan saja sehingga lebih praktis dan efisien. Mobile learning media menjadika pembelajaran menjadi unik karena pembelajar dapat mengakses materi, arahan dan aplikasi yang berkaitan dengan pembelajaran kapanpun dan dimanapun. Hal ini akan meningkatkan perhatian pada materi pembelajaran, membuat pembelajaran menjadi persuasif, dan dapat mendorong motivasi pembelajar kepada pembelajaran sepanjang hayat (lifelong learning) (Yuniati, 2012).

Berdasarkan hasil analisis uji kelayakan yang didapatkan yang juga diperkuat dengan hasilhasil penelitian yang telah ada maka penggunaan mobile learning media ini memberikan nilai positif dalam proses pembelajaran.

\section{KESIMPULAN}

Rata-rata hasil uji kelayakan oleh ahli materi didapatkan skor 83,27\% yang berarti layak dari sisi materi. Sedangkan oleh ahli media didapatkan skor $88,15 \%$ yang berarti layak dari sisi media pembelajaran. Berdasarkan hasil uji kelayakan yang dilakukan maka media pembelajaran fisika berbasis mobile learning pada materi fisika inti dan radioaktivitas layak digunakan sebagai salah satu media pembelajaran dengan nilai rata-rata 85,71\% dengan interpretasi sangat baik. Sehingga produk ini dapat diujicoba lapangan bagi pengguna agar didapatkan produk yang layak digunakan sebagai alternatif media pembelajaran di kelas. 


\section{DAFTAR PUSTAKA}

Ali, M. (2009). Pengembangan media pembelajaran interaktif mata kuliah medan elektromagnetik. Jurnal Edukasi Elektro, 5(1).

Araswati, D. S. L. (2016). Penggunaan Logger Pro Untuk Analisis Gerak Harmonik Sederhana Pada Sistem Pegas Massa. Faktor Exacta, 9(2), 119-124.

Damayanti, A. E., Syafei, I., Komikesari, H., \& Rahayu, R. (2018). Kelayakan Media Pembelajaran Fisika Berupa Buku Saku Berbasis Android Pada Materi Fluida Statis. Indonesian Journal of Science and Mathematics Education, 1(1), 63-70.

Gunadarma, Ananda. 2011. "Pengembangan Modul Elektronik Sebagai Sumber Belajar Untuk Mata Kuliah Multimedia Design". Artikel Ilmiah Tugas Akhir. Fakultas Ilmu Pendidikan Universitas Negeri Jakarta

Hayati, S., Budi, A. S., \& Handoko, E. (2015, October). Pengembangan media pembelajaran mobile learning media fisika untuk meningkatkan hasil belajar peserta didik. In Prosiding Seminar Nasional Fisika (E-Journal) (Vol. 4, pp. SNF2015-II).

Hayati, S., Budi, A. S., \& Handoko, E. (2015, October). Pengembangan media pembelajaran mobile learning media fisika untuk meningkatkan hasil belajar peserta didik. In Prosiding Seminar Nasional Fisika (E-Journal) (Vol. 4, pp. SNF2015-II).

Khairani, M., Sutisna, S., \& Suyanto, S. (2019). Studi Meta-Analisis Pengaruh Video Pembelajaran terhadap Hasil Belajar Peserta Didik. Jurnal Biolokus, 2(1), 158166.

Mardiyasa, P., Saputra, A., Wirawan, I. M. A., \& Arthana, I. K. R. (2016). Film Animasi Pembelajaran Sistem Pencernaan Manusia pada Kelas VIII SMP Negeri 3 Banjar Tahun Ajaran 2015 / 2016. Kumpulan Artikel Mahasiswa Pendidikan Teknik Informasi (KARMAPATI), 5(2).

Matsun, M., Ramadhani, D., \& Lestari, I. (2018). Pengembangan bahan ajar listrik magnet berbasis android di program studi pendidikan fisika IKIP PGRI pontianak. Jurnal Pendidikan Matematika dan IPA, 9(1), 99-107.

Megawati, C. (2014). Pengembangan Media Pembelajaran BIPA Tingkat Menengah Melalui E-Book Interaktif di Programincountry Universitas Negeri Malang Tahun 2014. NOSI, 2(1), 62-70.

Priscylio, G. (2019). Pengembangan Bahan Ajar Mandiri Pokok Bahasan Suhu dan Kalor Menggunakan Software Camtasia. Journal of Teaching and Learning Physics, 4(1), 50-64.

Purbasari, R. J., Kahfi, M. S., \& Yunus, M. (2013). Pengembangan aplikasi android sebagai media pembelajaran matematika pada materi dimensi tiga untuk peserta didik SMA kelas X.Jurnal Online Universitas Negeri Malang, 1(4), 1-10.

Ridwan, I. M. (2019). Penerapan Model Pembelajaran Berbasis Pengalaman untuk Meningkatkan Pemahaman Konsep Siswa. Journal of Teaching and Learning Physics, 4(1), 21-27.

Saraswati, D. L. (2018). Student Worksheet Based Inkuiri Social Interactions. In Journal of Physics: Conference Series (Vol. 1114, No. 1, p. 012025). IOP Publishing.

Saraswati, D. L. (2018). Development Of WebBased and E-Learning Media for Physics Learning Materials in Senior Hig School: A Pilot Study. In Journal of Physics: Conference Series (Vol. 1120, No. 1, p. 012029). IOP Publishing.

Saraswati, D. L., Azizah, R. N., Dasmo, D., Okyranida, I. Y., Sumarni, R. A., Mulyaningsih, N. N., \& Rangka, I. B. (2018, November). Development of web-based and e-learning media for physics learning materials in senior high school: a pilot study. In Journal of Physics: Conference Series (Vol. 1114, No. 1, p. 012025). IOP Publishing.

Saraswati, D. L., nenden Mulyaningsih, N., \& Widiyatun, F. (2018). Rancang Bangun Perangkat Alat Ukur Medan Magnet 
Portabel Berbasis Android. Jurnal

Pendidikan Fisika, 6(1), 54-60.

Sutopo, Ariesto Hadi. 2003. Multimedia Interaktif dengan Flash. Yogyakarta: Graha Ilmu.

Taufik, M., \& Kristanto, A. (2018). Pengembangan Mobile Learning Berbasis Aplikasi Android Mata Pelajaran Fisika Materi Listrik Arus Searah Kelas XI SMK Negeri 2 Kediri.Jurnal Mahasiswa Teknologi Pendidikan, 9(2).

Widada, W., \& Rosyidi, A. (2018). Perancangan Media Pembelajaran Fisika SMP Berbasis Multimedia Interaktif. IT CIDA, 3(2).

Widodoaji. 2013. Kompetensi Inti dan Kompetensi Dasar Fisika Kurikulum 2013. MGPM Fisika Banyumas.

https://mgmpfisikabanyumas.wordpress.c om/2013/05/17/kompetensi-inti-dan-

kompetensi-dasar-fisika-kurikulum-2013/ diakses pada 2 Agustus 2019.

Yektyastuti, R., \& Ikhsan, J. (2016). Pengembangan media pembelajaran berbasis android pada materi kelarutan untuk meningkatkan performa akademik peserta didik SMA.Jurnal Inovasi Pendidikan IPA, 2(1), 88-99.

Yuniati, L. (2012). Pengembangan media pembelajaran mobile learning efek doppler sebagai alat bantu dalam pembelajaran fisika yang menyenangkan. Jurnal Penelitian Pembelajaran Fisika, 2(2/septembe). 